\title{
INTERNET PLUS STRATEGY AS A FACTOR OF DEVELOPMENT OF ECONOMIC EDUCATION IN THE PEOPLE'S REPUBLIC OF CHINA
}

\author{
Kseniia Tsytsiura \\ Postgraduate Student, State Higher Educational Institution \\ "University of Educational Management", Ukraine \\ Foreign Expert of Jiaxing University, China \\ e-mail: ksenija.tsytsiura@gmail.com, orcid.org/0000-0002-4606-9287 \\ Gao Wanquan \\ Director of the College English Department, English Lecturer of Jiaxing University, China \\ e-mail: billgwq@gmail.com, orcid.org/0000-0001-8114-5129
}

\section{Summary}

The development of the Internet greatly influences the transformation and modernization of the industries and businesses in the People's Republic of China. As a result, the Chinese government has developed a special Internet Plus strategy to transform, modernize and equip conventional industries for joining the modern economy. This strategy is being implemented through the development of mobile devices, cloud services and new generation applications connecting people to social media, analytics and big data. Such development is going to attract foreign businesses planning to make an impact on the booming Chinese Internet economy, with the growing need for the experienced economists to assist their efforts.

The specific characteristics and the areas of application of Internet Plus in different industries have been summed up and characterized. The ways of application of Internet Plus in economic education of the People's Republic of China were substantiated. The effective mobile applications used for educational purposes with the economists in the higher educational institutions of the People's Republic of China were highlighted and analyzed. The recommendations to be applied in foreign economic education using the benefits of Internet Plus strategy were formulated.

Understanding and application of the Internet Plus strategy is a critical component for the economists in People's Republic of China and abroad to achieve career success and open future businesses to enter the Chinese and world market.

Keywords: industry, online learning model, mobile applications, higher educational institution, Economics.

DOI: https://doi.org/10.23856/3879

\section{Introduction}

Similar to the Information Superhighway and Industry 4.0, the concept of Internet Plus was first introduced to public by Ma Huateng, the Tencent CEO, in an article published in the People's Daily on April 21, 2014. He strongly believed that Internet Plus is a trend, and "Plus" stands for the connection between the Internet and all the traditional walks of life (Wang, 2016: 5-8).

In order to keep up with the development of information technology, Chinese Prime Minister, Li Keqiang first suggested the Internet Plus Action Plan in the government work report on March 5, 2015 (China unveils targets for 2015, 2015). He stated that the Internet Plus 
strategy was motivated by linking China's growing economy with the power of interconnected services. The government set out to connect various traditional industries with the world.

Charles Fan, EMC senior vice president, spoke to Chinese corporate decision makers about Internet Plus at a recent forum organized by VMware and the Chinese Academy of Engineering, pointing out that China's economy will have "radical change" due to the Plan (IT 2020 Forum, 2020).

Internet Plus is reckoned as an important driving force for the current development. It crosses time and regional constraints and organically combines the Internet with other traditional industries to promote social and economic development ( $L i$, 2017: 293-296). Because of the fact that Internet communication technologies (ICT) are widely spread and actively used in education of all levels, it has become really important to study the ways of application of Internet Plus in economic education of China as well as the possible ways in which the foreign economic education can benefit from this new developing strategy.

The aim of the study is to define the Internet Plus strategy and specify its characteristics, analyze its application in different industries and in economic education of students of higher educational institutions in the People's Republic of China, form the recommendations for the development of the foreign economic education by means of Internet Plus.

\section{Theoretical framework and research methods}

The issue of Internet Plus has been in the focus of numerous scholars within the last several years. The impact of Internet development on Chinese higher education was studied by Chen Q. Different models of web-based teaching in the Internet Plus era were investigated by Gao B., Cui G., Li R., Liu X., Ma F., Peng B., Qiao F., Wang H., Zhang L. The online applications used for teaching and learning within Internet Plus strategy were researched by Ju W., Li J., Tu S., Yang B., Zhou S., Zou B. The influence of Internet Plus teaching resources and models on students' performance and the teachers' response to them was investigated by Chen Y., Ding Z., Hoi C., Jia J., Li G., Lin L., Mao L., Mei B., Miao J., Sang G., Teo T.

The research methods used in this study are:

- theoretical methods: analysis (to study the definition and the characteristics of Internet Plus), generalization (to formulate conclusions and recommendations for applying Internet Plus in foreign economic education in higher educational institutions).

- empirical methods: observational (observation of the application of Internet Plus in economic education in the higher educational institution in China) - to determine the possible ways of application of the Internet Plus in the foreign economic education.

\section{Results of the study}

Internet Plus refers to the new model of industries based on the application of the Internet and other information technologies in conventional industries. It is an incomplete equation where various Internets (mobile Internet, cloud networking, big data or Internet of Things) can be attached to other fields, fostering new industries and business development in China.

China is pursuing the Internet Plus strategy to develop a new industrial ecosystem for the future, where various economic and social fields are integrated with the Internet through Internet platforms and ICT (Information and Communications Technologies). Together with Made in China 2025 strategic plan, Internet Plus strategy is significant for implementing innovations 
as China's new growth engine. It is believed to promote industrial advancement and formulate an effective response to the 4th Industrial Revolution (Lee, 2019).

Internet Plus is a countrywide strategy implemented with the help of the State government of China driven by the belief that the Internet is set to transform industries. All the industries like energy sector, automobiles, manufacturing will need to be transformed to take advantage of Internet technologies to increase productivity and competitiveness (IT 2020 Forum, 2020). One of the country's leading tech entrepreneurs Pony Ma, who is a chairman and founder of mobile gaming and social media giant called Tencent, states that the aim of the Internet Plus is not only to simply encourage connections between the Internet industry and traditional economy sectors but also to forge a process of innovating new models, technologies and applications.

\section{Internet Plus specific characteristics and areas of application}

Internet Plus Action Plan is expected to promote Chinese economy through innovation and reformation of economic structure. China's emerging Internet Plus has the following six characteristics: transboundary integration, openness, structure transformation, omnipresent connectivity, human-centric nature and innovation-driven model. Let's consider all these characteristics in detail (see Figure 1).

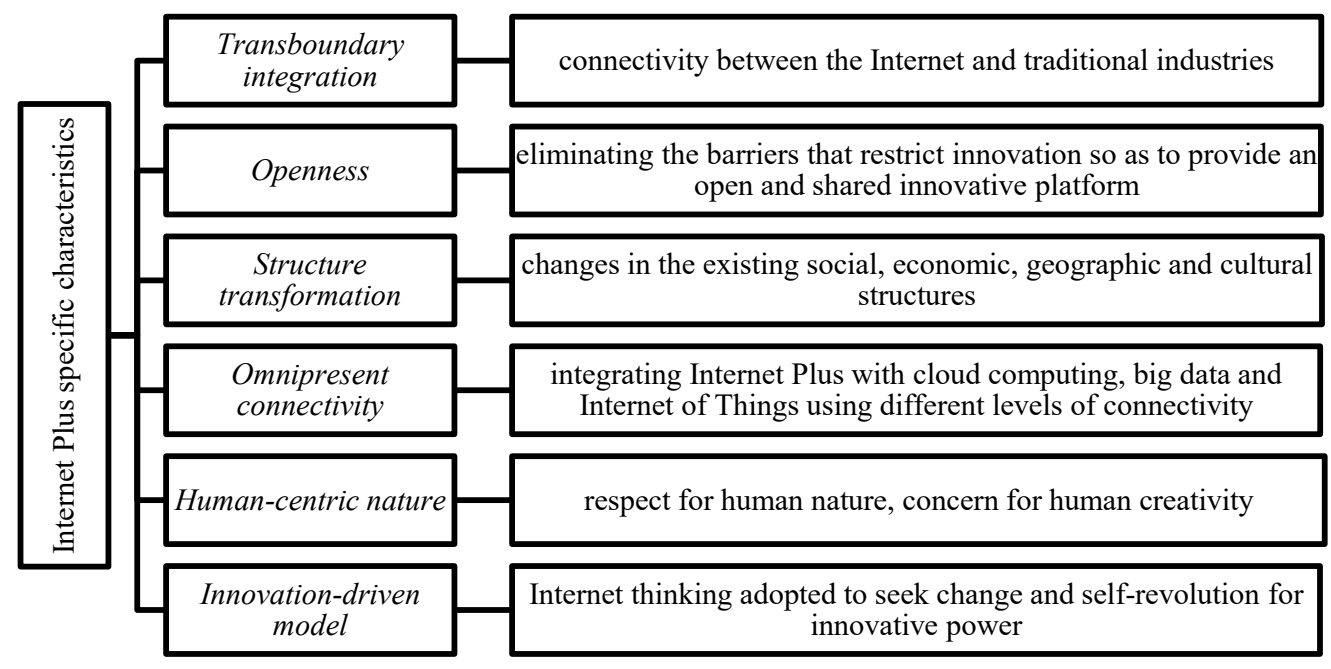

Figure 1. Internet Plus Specific Characteristics

Source: developed by the authors

All these specific characteristics vividly explain the motivation to connect the rapidly developing economy of China to the power of connected services. The Internet Plus development plan stipulates the integration of cloud computing, big data and the Internet of Things with a variety of industries ranging from manufacturing to commerce, internet banking and education.

Internet Plus will help different industries to optimize and better serve customers through technologies such as cloud computing and artificial intelligence (AI). Other areas that may benefit from this technology include finance, medical system, government, agriculture, transportation, and education, etc (Zeng, 2015: 42-49). These areas are shown in Figure 2. 


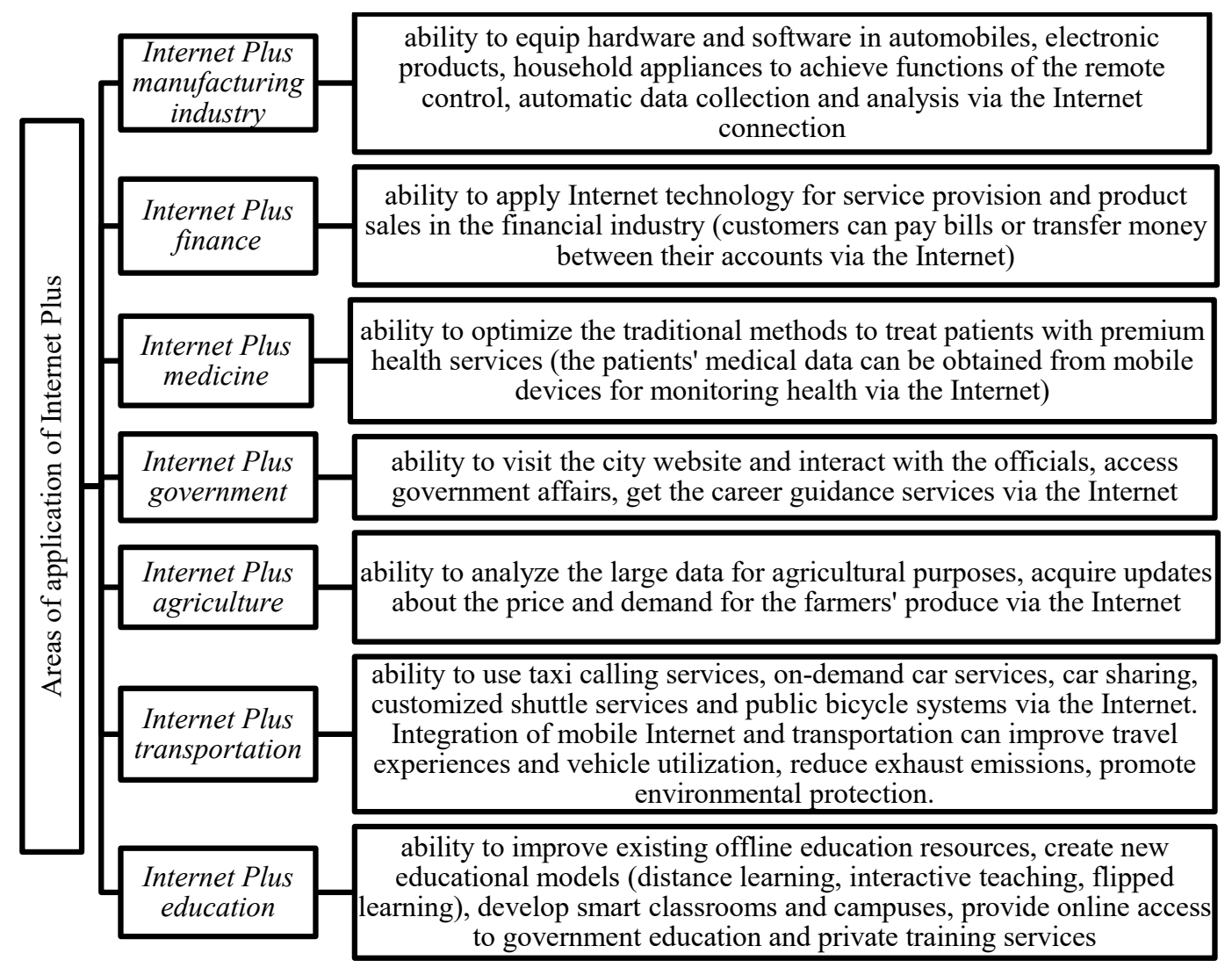

Figure 2. Areas of Application of Internet Plus

Source: developed by the authors

\section{Application of Internet Plus in higher economic education}

Under the guidance of Internet Plus Action Plan, the Internet Plus Education is gradually developing and achieving high progress recently. "The Opinions on Strengthening the Application and Management of Online Open Courses in Colleges and Universities in 2015" (Wang, 2019), issued by the Ministry of Education of China, promoted the development of online teaching and learning in colleges and universities, which is a great challenge as well as the opportunity for Chinese higher education to improve.

Significant changes are taking place in economic education of Chinese colleges and universities. The studying model of college and university students is gradually changing from the traditional one to the flipped and blended models with the use of online learning resources. The experimental research of Chinese scholars in the field of pedagogy shows that such models can contribute into the development of the students' listening and speaking skills (Cui, 2014: 447-460), (Wang, W., 2017: 516-519) as well as improve their general academic performance. It can be very useful for the students majoring in Economics because intercultural communication skills are vitally important for their future business activities in domestic and international markets. 
Compared with traditional teaching, online learning models in Chinese economic education show the following five distinctive features:

\section{(1) Spanning time and space of teaching and learning}

Traditional teaching must be conducted at specific time and in specific places such as classrooms and labs, however online learning models are no longer limited to face-to-face learning. Synchronous live teaching and learning can be conducted through computers, tablets, mobile phones and other devices. Teachers can give tasks, provide resources, answer questions and conduct assessments online while students can engage themselves in study at any location and any time having the ability to discuss what they've learned with teachers and peers. To a large extent, teaching and learning happen beyond the limitation of time and space.

\section{(2) Personalized teaching and learning}

In the traditional higher economic education model, it is difficult for teachers to pay attention to all the students who have different motivation, abilities, methods of perceiving the information and outcomes of their study. The personalized online learning can meet the various requirements of different students ( $\mathrm{Li}, 2020$ : 111). Students can collect relevant information on mobile devices according to their own learning progress and get timely support when they encounter problems. This approach can greatly contribute into student-centered and inclusive education.

\section{(3) Situational teaching and learning}

The diversity of online learning environment allows teachers to set specific scenarios for real problems in learning, which help students understand and internalize what they are supposed to learn in specific situations as well as increase the sense of authenticity and their learning involvement. Situation modeling in online learning which is often used in problem-based learning approach can deepen the students' understanding of relevant knowledge and contribute to putting it into practice so that students can transfer what they learn into skills (Lin, 2017: 109-125).

\section{(4) Multi-directional interaction in teaching and learning}

It was mentioned that the traditional teaching is mostly a one-to-many mode from teacher to students, while the online learning via mobile devices is not restricted by time and space. It doesn't only contribute into the interaction between students and teachers, but also enables to create study groups among students, share learning experience, encourage discussion and teamwork, thus improving learning efficiency and the formation of the soft skills which are important for the professional economic activity of the future economists.

\section{(5) Diversified online teaching and learning resources}

The Internet contains a large amount of learning resources and timely updates. Students can search for the learning resources at any time to meet their individual demands. Massive online open courses (MOOC) can provide college students with academic materials, cultivate their interests and hobbies, and enhance their practical and comprehensive skills (Gao, 2019: 138-146). Although MOOC is in the developmental stage in China, it has already shown good effect in the Chinese economic education within the global pandemic period when distance learning became the only possible way to continue the educational process in higher educational institutions.

It's important to note that in the era of Internet Plus Education, mobile terminal technology and wireless network technology make it possible to access Internet using various online teaching and learning applications with the easy access to online learning resources. 188 different applications with different functions that can be used to extend and deepen teaching and learning are collected and shown in the "Padagogy Wheel 5.0", developed by the Australian researcher Allan Carrington (Carrington, 2013). 
Currently, thanks to the Internet Plus strategy there is more than a dozen of online teaching and learning applications used for teaching students majoring in Economics in Chinese colleges and universities, including various professional online teaching and learning applications, teaching-assistant mini apps, video conference applications and social networking applications. They can be used separately or combined to achieve better teaching effect. In this research we made a detailed review of the applications that have already proven their effectiveness in distance learning process of the students majoring in Economics in difficult epidemiological conditions within the second studying semester of 2019-2020 in Chinese universities. Let's consider each group of the applications with examples in detail.

(1) Professional online teaching and learning applications. Superstar mobile app (www. chaoxing.com) and Wisdom Tree mobile app (www.zhihuishu.com) are the most typical applications of this kind. Teachers can upload syllabus, teaching plans, video materials, assignments and other resources onto these teaching platforms. Students can preview or review the information through mobile phones, tablets or computers with teachers being able to easily open video sessions to interact with them, grade students' homework, track and manage their learning progress and behaviors as well as handle student affairs.

Superstar mobile app can be used to track attendance of students. It is also very handy to check whether students understand the lecture content by holding mini tests either in or after class, which can automatically generate testing results. Teachers can make use of quiz games in the app to interact with students, which helps to involve the whole group into the learning process thus developing the students' communicative competence. The online pop-up question $\&$ answer and offline real-time interaction provided by Wisdom Tree offer a perfect solution to the lack of teacher-student interaction in traditional classroom teaching.

(2) Teaching-assistant mini apps. WeChat (www.wechat.com) is a mobile app which has various functions including communication in the messenger via audio and video calls, online shopping and digital payment as well as the mobile teaching and learning opportunities (Tu, 2018: 555-560). It has the possibility to integrate the mini apps for education. These apps are called "mini" because they can be easily used in Wechat without actual application installing. The most popular two are Rain Classroom and Teachermate.

Rain Classroom is more focused on the real-time feedback in classroom teaching and learning. With the use of Rain Classroom, teachers can synchronize PPT (PowerPoint) materials containing MOOC videos, exercises, and voice messages with students' mobile phones. The "bullet screen" function enables teachers to instantly check the amount of the teaching material that the students managed to study and motivate them to preview and learn this material with the following discussion in face-to-face classes. This approach is characteristic for the flipped classroom teaching model (Zhang, 2018: 3652-3661). The students' engagement and classroom interaction can be effectively facilitated by means of Rain Classroom. It covers the whole before-in-after-class stages, providing teachers and students with complete three-dimensional data support, personalized reports and automatic task reminders to ensure the transparent teaching and learning process. (Zhang, 2017: 94-96).

Teachermate is a classroom interactive application, which is practical and easy to operate. This application focuses on the student assessment providing multiple interactive functions such as signing-in, classroom testing, and classroom discussion. Students can perform all the operations in a relatively short time period being encouraged by gamification methods to actively participate in interactive activities in the classroom. Chinese, Vietnamese and Australian researchers believe that the benefits of gamification of learning in higher economic education can be used for the curriculum design (Wang, F., 2017: 130-144), (Nguyen, 2020: 34-39). 
(3) Video conference applications. Tencent VooV Meeting (https://intl.cloud.tencent.com/ product/tvm), DingTalk (www.dingtalk.com) and Zoom (www.zoom.us) are the most widely used video conference applications in China. Owing to features of large capacity, screen sharing, high video and audio quality, they have become the main driving forces of online live teaching and learning in Chinese colleges and universities. When teaching and learning online, teachers can interact with students in real time through voice or text. Zoom provides excellent grouping functions, with the help of which students can be randomly divided into groups for online discussions. This function highly contributes into the communicative teaching approach and helps to develop their communicative competence. (Tang, 2019: 161-162).

(4) Social networking applications. Being the most popular and most used social networking applications in China, WeChat and QQ (www.imqq.com) have become indispensable communication tools used among teachers and students, as well as the important platform for online teaching and learning. WeChat and QQ have staggering number of registered monthly active users -1 billion and 783 million respectively. Almost all college teachers and students have both WeChat and QQ accounts. Through the Internet connection, WeChat and QQ support the uploading and downloading of different educational materials such as texts, pictures, videos and PPT presentation materials. With the voting function of WeChat and QQ, teachers can organize mini tests as a handy way to check students' mastery of the knowledge acquired. In addition, assignments can be submitted by students in QQ for teachers' correction, grading and feedback.

The research on students' perceptions of mobile learning shows that instant messaging and asynchronous communication have become a bridge for teachers and students to share their learning experience, expanding the time and space of teaching and learning infinitely, thus improving the students' motivation to learn (Kim, 2013: 52-73).

So, with the help of online teaching and learning applications the learning materials can be shared, discussed and analyzed them by means of online communication. It enables students in general and economists in particular to study, develop professional skills and express their opinions online without being limited by time and space.

\section{Recommendations for the development of foreign economic education by means of Internet Plus}

Inspired by the experience of Chinese economic education with application of Internet Plus, foreign economic education can also benefit from the development of this strategy if the following four recommendations are taken into consideration:

(1) Development of the Strategic Plan and Policy

Considering the example of the Internet Plus Action Plan in the government work report and "The Opinions on Strengthening the Application and Management of Online Open Courses in Colleges and Universities", both made public in 2015 by the government of the People's Republic of China, the corresponding strategies, plans and policies concerning ICT in education are fundamental for the development of the foreign economic education.

(2) Ensuring the Adequate Infrastructure and Accessibility

Without adequate infrastructure and accessibility to teaching and learning resources, strategic plans and policies can hardly be effective. Broadband and mobile infrastructure investments are required to establish the environment framework, coupled with supportive governance for the Internet ecosystem. Broadband and mobile networks, affordable connectivity, easy access is essential if teachers and students expect to make full use of what the Internet can offer. 


\section{(3) Providing Open Access to Massive Resources and Devices}

Economic education via the Internet provides open access to massive resources in this field which are explicitly educational in purpose and can supplement the curricula for the students majoring in Economics in the foreign countries. Chinese researchers believe that instead of primarily relying on textbooks, students can get the ability explore massive online resources like OER (Open educational resources) and MOOC (Massive Online Open Courses) thus developing their professional skills (Xiong, 2018: 3529-3535). However, it should be taken into account that the integration in the educational environment in order to benefit from the advantages of the Internet Plus education can't be implemented without the open access to the digital devices used in and out of classroom.

(4) Further Development of Digital Literacy and Digital Competence

With the rapid development of ICT in economic education, the formation of digital literacy and digital competence is crucial for both teachers and students to maximize the value of Internet Plus education. Digital devices and learning applications have proved to be productive for Chinese students' online learning, and foreign students can also develop their skills in using computers and other digital devices, as well as the learning applications for studying. Teachers should also be motivated to acquire new digital skills of the 21 st century that can help to make full use of Internet resources and platforms for educational purposes.

Chinese experience has shown the significance of developing teachers' abilities to merge ICT and new teaching models in and out of classroom (Peng, 2017: 41-50), (Liu, 2017: 3363-3365).

\section{Conclusions}

By 2025, China's new Internet Plus strategy will have become a new economic model and one of the leading factors of economic and social innovation and development. This strategy has already influenced and will keep having a significant influence on businesses across all industries. Being a Chinese nationwide policy, it brings great opportunities to the economic education in the People's Republic of China. Online teaching and learning have been widely introduced in schools and universities, which helps to change the ways how teachers give knowledge and how students accept it.

We believe that with the current Internet Plus development in economic education, both teachers and students not only in the People's Republic of China but also in the foreign countries can benefit from integration of Internet and technology in achieving comprehensive teaching and learning experience. With the Internet connection available almost anywhere and anytime and the Internet development strategies and policies concerning ICT in education, students can have access to online educational resources through the devices such as laptops, tablets and mobile phones, and learn not being limited by time and space, which means that the education costs can be sharply lowered and the effectiveness of learning can be greatly improved.

Our further research will be focused on the analysis of the application of Internet Plus in education of the students of different majors as well as the institutions of other educational levels.

\section{Acknowledgments}

This work is partially supported by the second batch of collaborative education projects of the Ministry of Education of China in 2019 (No. 201902243032), Research Program on the Development of Foreign Language Teachers' Information Literacy and Teaching Ability. The authors thank all our colleagues for their discussion and suggestions. 


\section{References}

Carrington, A. (2013). The Padagogy Wheel English V5. Retrieved from https:// designingoutcomes.com/english-speaking-world-v5-0/ [in English].

China unveils targets for 2015: Li Keqiang's speech as it happened. (2020). Retrieved from https://www.scmp.com/news/china/article/1729846/live-li-keqiang-unveils-chinas-annualwork-report [in English].

Cui, G. (2014). An experimental research on blended learning in the development of listening and speaking skills in China. Southern African Linguistics and Applied Language Studies, 32(4), 447-460. doi: 10.2989/16073614.2014.999989 [in English].

Gao, B. (2019). Highly Efficient English MOOC Teaching Model Based on Frontline Education Analysis. International Journal of Emerging Technologies in Learning (Ijet), 14(06), 138-146. doi: 10.3991/ijet. v14i06.10160 [in English].

IT 2020 Forum Shows Promise of "Internet Plus" in China |VMware Radius. (2020). Retrieved from https://www.vmware.com/radius/it-2020-forum-shows-promise-of-internet-plus-in-china/ [in English].

Jianqiu, Z., \& Mengke, Y. (2015). Internet plus and networks convergence. China Communications, 12(4), 42-49. doi: 10.1109/cc.2015.7114068 [in English].

Kim, D., Rueckert, D., Kim, D.-J., \& Seo, D. (2013). Students' perceptions and experiences of mobile learning. Language Learning \& Technology, 17(3), 52-73. [in English].

Lee, S. (2019). China's Internet Plus Strategy: Characteristics and Regional Case Study. World Economy Brief, 9(23). [in English].

Li, H. (2017). The Development of Higher Education in the Era of "Internet Plus". 4th International Conference on Education, Management, Arts, Economics and Social Science, 172, 293-296. [in English].

Li, X. (2020). Analysis on College English Teaching Reform and Development Under the Background of Internet Plus. 5th International Conference on Social Sciences and Economic Development, 427, 110-113. doi: 10.2991/assehr.k.200331.023 [in English].

Lin, L. (2017). Impacts of the Problem-based Learning Pedagogy on English Learners' Reading Comprehension, Strategy Use, and Active Learning Attitudes. Journal of Education and Training Studies, 5(6), 109-125. doi: 10.11114/jets. v5i6.2320 [in English].

Liu, M. (2017). Research on College English Teaching Reform under "Internet Plus Applied Talent" Training Mode. Agro Food Industry Hi-Tech, 28(3), 3363-3365. [in English].

Nguyen, L., Nguyen, L., \& Tan, G. (2020). Gamification in Business Education. In Proceedings of the 2020 2nd International Conference on Modern Educational Technology, 34-39. doi: 10.1145/3401861.3401867 [in English].

Peng, B. (2017). Construction and Application of the BEST Teaching Mode of College English in Big Data. International Journal of Emerging Technologies in Learning, 12(09), 41-50. doi: 10.3991/ijet. v12i09.7483 [in English].

Tang, T., \& Jia, D. (2019). The Cultivation of English Majors' Intercultural Communicative Competence Based on PBL Model in the Environment of Computer Network. Basic \& Clinical Pharmacology \& Toxicology, 238(124), 161-162. [in English].

Tu, S., Yan, X., Jie, K., Ying, M., \& Huang, C. (2018). WeChat: An applicable and flexible social app software for mobile teaching. Biochemistry and Molecular Biology Education, 46(5), 555-560. doi: 10.1002/bmb.21170 [in English].

Wang, F., Wang, Y., \& Hu, X. (2017). Gamification Teaching Reform for Higher Vocational Education in China: A case study on Layout and Management of Distribution Center. International 
Journal of Emerging Technologies in Learning (Ijet), 12(09), 130-144. doi: 10.3991/ijet. v12i09.7493 [in English].

Wang, S. (2019). Construction and Application of Online Open Courses in Independent Colleges Against the Background of "Internet Plus Education". 5th International Conference on Economics, Management, Law and Education. Advances in Economics, Business and Management Research, 1134-1137. doi: 10.2991/aebmr.k.191225.221 [in English].

Wang, W. (2017). Blended Learning-based English Teaching Mode among New English Majors. Agro Food Industry Hi-Tech, 28(1), 516-519. [in English].

Wang, Z., Chen, C., Guo, B., Yu, Z., \& Zhou, X. (2016). Internet Plus in China. IT Professional, 18(3), 5-8. doi: 10.1109/mitp.2016.47 [in English].

Xiong, Q. (2018). College English MOOC Teaching on SWOT Analysis. Educational Sciences: Theory \& Practice, 18(6), 3529-3535. doi: 10.12738/estp.2018.6.263 [in English].

Zhang, L. (2018). English Flipped Classroom Teaching Model Based on Cooperative Learning. Educational Sciences: Theory \& Practice, 18(6), 3652-3661. doi: 10.12738/estp.2018.6.278 [in English].

Zhang, G. (2017). On the reformation of higher educational institutions with the background of Rain Classroom. China Adult Education, 19(2), 94-96 [in English]. 